\title{
SOME CHARACTERIZATIONS OF P-CONTINUITY AND NEW DECOMPOSITIONS
}

\section{Arafa A. Nasef}

Department of Physics and Engineering Mathematics, Faculty of Engineering;Kafr Elsheikh University, Kafr Elsheikh, Egypt.E-Mail: nasefa50@yahoo.com

\section{(Received: 22 July 2007)}

Abstract: The aim of this paper is to present the notion of relatively almost pcontinuity and $\mathrm{p}^{*}$-continuity and we obtain some decomposition theorems of $\mathrm{p}$ continuity by proving that,

1. A function $f: \mathrm{X} \rightarrow \mathrm{Y}$ is $\mathrm{p}$-continuous if and only if it is almost $\mathrm{p}$-continuous and relatively almost $\mathrm{p}$-continuous,

2. A function $f: \mathrm{X} \rightarrow \mathrm{Y}$ is $\mathrm{p}$-continuous if and only if it is almost $\mathrm{p}$-continuous and $\mathrm{p}^{*}$ continuous.

2000 Mathematics Subject Classification; 54 C8, 54 C10.

Key words and Phrases : p-continuous, almost p-continuous, $p^{*}$-continuous, relatively almost p-continuous.

\section{Introduction}

The decomposition of continuity is a classical problem of Real Analysis. Recently, El Naschie et al. [6-8] have pointed out that topology plays a significant role in quantum physics, high energy physics and superstring theory. One of the most important subjects in studying topology is continuity which have been researched by many mathematicians. A weaker form of continuity associated with preopen sets was considered back in 1982, when Mashhour et al. [14] introduced the concept of precontinuity. A function $f: \mathrm{X} \rightarrow \mathrm{Y}$ is called precontinuous [14] if the inverse image of every open subeset of $\mathrm{Y}$ is preopen in $\mathrm{X}$. Blumberg [2] proved that every function $f: \mathbf{R} \rightarrow \mathbf{R}$ is nearly continuous on a dense set of the real line $\mathbf{R}$. Since the begining of the 80 s, the name precontinuity dominates in the literature although the term near continuity is also ofen used. The following result shows the importance of precontinuity. "Every linear function from one Banach space to another Banach space is precontinuous"[16]. Note also that in Functional Analysis, precontinuous function are important in the context with the well known closed graph and open mapping theorems.

In 1990, Abd E1-Monsef et al.[1] introduced and studied a common strengthening of continuity and preirresoluteness called strongly M-precontinuous functions (written in short as p-continuous) by requiring the inverse image of each preopen set in the codomain to be open in the domain. The aim of this paper is to introduce the notion of relatively almost $\mathrm{p}$-continuity and $\mathrm{p}^{*}$-continuity and obtain decompositions of p-continuity. 


\section{Some preliminary topological concepts}

Throughout this note, $\mathrm{X}$ and $\mathrm{Y}$ are always topological spaces. The closure and the interior of a set $\mathrm{A} \subset \mathrm{X}$ are denoted by $\mathrm{Cl}(\mathrm{A})$ and $\operatorname{Int}(\mathrm{A})$, respectively. $\mathrm{A}$ subset $\mathrm{A}$ of $\mathrm{X}$ is said to be preopen [14] (=nearly open or locally dense [3]) if $\mathrm{A} \subset \operatorname{Int}(\mathrm{Cl}(\mathrm{A})$ ). The complement of a preopen set is called preclosed. The intersection of all preclosed sets containing a subset $\mathrm{A}$ is called the preclosure [5] of $\mathrm{A}$ and is denoted by $\mathrm{pCl}(\mathrm{A})$. The family of all preopen sets of $X$ is denoted by $P O(X)$. For a point $x$ in $X$, we set $P O(X, x)=\{U: x \in U \in P O(X)\}$.

Definition 2.1. A function $f:(\mathrm{X}, \tau) \rightarrow(\mathrm{Y}, \sigma)$ is said to be (1)strongly $\mathrm{M}$-precontinuous [1] (or p-continuous) if for each $\mathrm{x} \in \mathrm{X}$ and each preopen set $\mathrm{V} \subseteq \mathrm{Y}$ containing $f(\mathrm{x})$, there exists an open set $\mathrm{U} \subseteq \mathrm{X}$ containing $\mathrm{x}$ such that $f(U) \subseteq V$ (2)almost p-continuous [11] (or $p(\theta)$-continuous [4]) if for each $x \in X$ and each preopen set $\mathrm{V} \subseteq \mathrm{Y}$ containing $f(\mathrm{x})$, there exists an open set $\mathrm{U} \subseteq \mathrm{X}$ containing $\mathrm{x}$ such that $f(\mathrm{U}) \subseteq \mathrm{pCl}(\mathrm{V})$.

Definition 2.2. A function $f: \mathrm{X} \rightarrow \mathrm{Y}$ is called relatively almost $\mathrm{p}$-continuous at $\mathrm{x} \in \mathrm{X}$ if for each $\mathrm{V} \in \mathrm{PO}(\mathrm{Y}, f(\mathrm{x}))$, the set $f^{-1}(\mathrm{~V})$ is open in the subsapce $f^{-1}(\mathrm{pCl}(\mathrm{V}))$.

The function $f$ is called relatively almost p-continuous if it has this property at each point $\mathrm{x}$ of $\mathrm{X}$.

The pre-frontier or the preboundary [19] of a subset $A$ of $X$, denoted by $\operatorname{pFr}(\mathrm{A})$, is defined by $\operatorname{pFr}(\mathrm{A})=\mathrm{pCl}(\mathrm{A}) \cap \mathrm{pCl}(\mathrm{X} \backslash \mathrm{A})$.

Definition 2.3. A function $f: X \rightarrow Y$ is called $\mathrm{p}^{*}$-continuous if for each $\mathrm{V} \in \mathrm{PO}(\mathrm{Y})$, $f^{-1}(\mathrm{pFr}(\mathrm{V}))$ is closed in $\mathrm{X}$.

Remark 2.1. By means of easy examples on finite topological spaces one can see that almost p-continuity and relatively almost p-continuity are independent of each other. The same is also true for almost $\mathrm{p}$-cơntinuity and $\mathrm{p}^{*}$-continuity.

\section{On p-continuity}

For any space $(X, \tau)$ let $\tau_{p}$ be the smallest topology on $X$ containing $\mathrm{PO}(\mathrm{X}, \tau)$. The topology $\tau^{\alpha}[10]$ is $\operatorname{PO}(X, \tau) \cap S O(X, \tau)$ where $A \in S O(X, \tau)$ if and only if $A$ is semi-open [13] i.e. $A \subseteq C 1(\operatorname{Int}(A))$.Thus, for any space $(X, \tau), \tau \subseteq \tau^{\alpha} \subseteq P O(X, \tau) \subseteq \tau$. It is also known that $\mathrm{PO}\left(\mathrm{X}, \tau^{\alpha}\right)=\mathrm{PO}(\mathrm{X}, \tau)$ (Corollary 1 of $\left.[21]\right)$.

Lemma 3.1. A function $f:(\mathrm{X}, \tau) \rightarrow(\mathrm{Y}, \sigma)$ is $\mathrm{p}$-continuous if and only if $f:(\mathrm{X}, \tau) \rightarrow\left(\mathrm{Y}, \sigma_{\mathrm{p}}\right)$ is continuous.

Proof. A basic open set in $\sigma_{p}$ has the form $V=\cap\left\{B_{k}: k=1,2, \ldots, n\right\}$ where each $\mathrm{B}_{\mathrm{k}} \in \mathrm{PO}(\mathrm{Y}, \sigma)$. So if $f:(\mathrm{X}, \tau) \rightarrow(\mathrm{Y}, \sigma)$ is p-continuous, and $\mathrm{V}$ is a basic open set in $\sigma_{\mathrm{p}}$, $f^{-1}(\mathrm{~V})=\cap\left\{f^{-1}\left(\mathrm{~B}_{\mathrm{k}}\right): \mathrm{k}=1,2, \ldots, \mathrm{n}\right\} \in \tau$, so that $f:(\mathrm{X}, \tau) \rightarrow\left(\mathrm{Y}, \sigma_{\mathrm{p}}\right)$ is continuous. The converse is clear since $\mathrm{PO}(\mathrm{Y}, \sigma) \subseteq \sigma_{\mathrm{p}}$.

Remark 3.1. A function $f:(\mathrm{X}, \tau) \rightarrow(\mathrm{Y}, \sigma)$ is said to be weakly continuous [12] if for each $\mathrm{x} \in \mathrm{X}$ and each open set $\mathrm{V} \subseteq \mathrm{Y}$ containing $f(\mathrm{x})$, there exists an open set $\mathrm{U} \subseteq \mathrm{X}$ containing $\mathrm{x}$ such that $f(\mathrm{U}) \subseteq \mathrm{Cl}(\mathrm{V})$.

We observe that the following relations hold:

$$
\text { p-continuity } \rightarrow \text { almost p-continuity } \rightarrow \text { weak continuity }
$$


Definition 3.1. The graph $\mathrm{G}(f)$ of a function $f:(\mathrm{X}, \tau) \rightarrow(\mathrm{Y}, \sigma)$ is said to be strongly pclosed [10] if for each $(\mathrm{x}, \mathrm{y}) \in(\mathrm{XxY}) \backslash \mathrm{G}(f)$, there exist an open set $\mathrm{U} \subseteq \mathrm{X}$ containing $\mathrm{x}$ and a preopen set $\mathrm{V} \subseteq \mathrm{Y}$ containing y such that $(\mathrm{UxpCl}(\mathrm{V})) \cap \mathrm{G}(f)=\varnothing$ (or,equivalently, $\mathrm{f}(\mathrm{U}) \cap \mathrm{pCl}(\mathrm{V}))=\varnothing)$.

Recall that a space $(X, \tau)$ is called pre-Urysohn [18] if for any two distinct points $\mathrm{X} \neq \mathrm{y}$ there exist preopen sets $\mathrm{U}, \mathrm{V} \subseteq \mathrm{X}$ such that $\mathrm{x} \in \mathrm{U}, \mathrm{y} \in \mathrm{V}$ and $\mathrm{pCl}(\mathrm{U}) \cap \mathrm{pCl}(\mathrm{V}))=\varnothing$.

A space $(X, \tau)$ is called pc-compact [10] if every preclosed subset of $(X, \tau)$ is p-closed relative to $(\mathrm{X}, \tau)$.

Theorem 3.1. If $f:(\mathrm{X}, \tau) \rightarrow(\mathrm{Y}, \sigma)$ is p-continuous and $(\mathrm{Y}, \sigma)$ is pre-Urysohn, then $\mathrm{G}(f)$ is strongly p-closed.

Proof . Let $(\mathrm{x}, \mathrm{y}) \in(\mathrm{XxY}) \backslash \mathrm{G}(f)$, i.e $f(\mathrm{x}) \neq \mathrm{y}$. Since $(\mathrm{Y}, \sigma)$ is pre-Urysohn, there exist preopen sets $\mathrm{V}, \mathrm{W} \subseteq \mathrm{Y}$ containing $f(\mathrm{x})$ and $\mathrm{y}$, respectively, such that $\mathrm{pCl}(\mathrm{V}) \cap \mathrm{pCl}(\mathrm{W})$ $=\varnothing$. Since $f$ is $\mathrm{p}$-continuous, there exists an open set $\mathrm{U} \subseteq \mathrm{X}$ containing $\mathrm{x}$ such that $f$ $(\mathrm{U}) \subseteq \mathrm{V} \subseteq \mathrm{pCl}(\mathrm{V})$. Hence $f(\mathrm{U}) \cap \mathrm{pCl}(\mathrm{V})=\varnothing$, and so $\mathrm{G}(f)$ is strongly p-closed.

Definition 3.2. A subset $A$ of $(X, \tau)$ is called $p$-closed relative to $(X, \tau)[17]$ if every cover of $A$ by preopen sets of $(X, \tau)$ has a finite subfamily whose preclosures cover A.

The following result follows directly from the above definitions and Theorem 3.1.

Corollary 3.1. Let $f:(X, \tau) \rightarrow(Y, \sigma)$ be a function where $(Y, \sigma)$ is pre-Urysohn and pccompact. Then the following properties are equivalent:

(a) $f$ is p-continuous,

(b) $f$ is almost p-continuous,

(c) G $(f)$ is strongly p-closed,

(d) $f^{1}(\mathrm{~K})$ is closed for each subset $\mathrm{K} \subseteq \mathrm{Y}$ which is p-closed relative to $(\mathrm{Y}, \sigma)$.

Recall that space $X$ is resolvable if there is a dense subset $D \subseteq X$ for which $X \backslash D$ is also dense in $\mathrm{X}$.

Lemma 3.2 (Corollary 5 of [9]) If $(X, \tau)$ is resolvable, then $\tau_{p}=2^{X}$.

Proof. Let $E_{1}$ and $E_{2}$ be disjoint dense subset of $X$ and let $x \in X$. Then $E_{i} \cup\{x\}$ where $\mathrm{i}=1,2$ are dense and hence preopen. Then $\{x\}=\left(E_{1} \cup\{x\}\right) \cap\left(E_{2} \cup\{x\}\right) \in \tau_{p}$.

Theorem 3.2. Let either every open subset of $\mathrm{Y}$ be closed, or $(\mathrm{Y}, \sigma)$ be resolvable, then a function $f:(\mathrm{X}, \tau) \rightarrow(\mathrm{Y}, \sigma)$ is p-continuous if and only if $f:(\mathrm{X}, \tau) \rightarrow\left(\mathrm{Y}, 2^{\mathrm{Y}}\right)$ is continuous.

Proof. By Lemma 3.1 and Lemma 3.2 and the foregoing remarks, in either case, we have $\sigma_{\mathrm{p}}=2 \mathrm{Y}$.

Corollary 3.2. If $(\mathrm{Y}, \sigma)$ is resolvable, the following are equivalent:

(a) $f:(\mathrm{X}, \tau) \rightarrow(\mathrm{Y}, \sigma)$ is $\mathrm{p}$-continuous,

(b) $f^{-1}(\mathrm{~V})$ is clopen (closed and open) for each $\mathrm{V} \subseteq \mathrm{Y}$,

(c) $f^{-1}$ (W) is clopen for each $\mathrm{W} \subseteq \mathrm{Y}$,

(d) $f^{-1}(\mathrm{~W})$ is open for each $\mathrm{W} \subseteq \mathrm{Y}$,

(e) $f:(\mathrm{X}, \tau) \rightarrow\left(\mathrm{Y}, 2^{\mathrm{Y}}\right)$ is continuous.

Proof. It follows from Lemma 3.1 and Lemma 3.2.

Corollary 3.3. If $(\mathrm{X}, \tau)$ is connected and $(\mathrm{Y}, \sigma)$ is resolvable, then $f:(\mathrm{X}, \tau) \rightarrow(\mathrm{Y}, \sigma)$ is pcontinuous if and only if $f$ is a constant function. 
For example if $\mathbf{R}$ is the usual space of real numbers, every non-constant function $f: \mathbf{R} \rightarrow \mathbf{R}$ is not p-continuous.

Corollary 3.4. If $(\mathrm{X}, \tau)$ is dense-in-itself (has no isolated points) and $(\mathrm{Y}, \sigma)$ is a nonempty resolvable space then there is no $\mathrm{p}$-continuous injection $f:(\mathrm{X}, \tau) \rightarrow(\mathrm{Y}, \sigma)$.

\section{New decomposition of p-continuity}

Theorem4.1. A function $f: \mathrm{X} \rightarrow \mathrm{Y}$ is $\mathrm{p}$-continuous if and only if it is almost pcontinuous and relatively almost $\mathrm{p}$-continuous.

Proof. We prove only the sufficient condition since the necessary condition is evident. Let $\mathrm{V} \in \mathrm{PO}(\mathrm{Y})$. Since $f$ is relatively almost $\mathrm{p}$-continuous, we have $f^{-1}(\mathrm{~V})=$ $f^{-1}(\mathrm{pCl}(\mathrm{V})) \cap \mathrm{G}$ for some open set $\mathrm{G}$ of $\mathrm{X}$. Suppose that $\mathrm{x} \in f^{-1}(\mathrm{~V})$. It follows that $f(\mathrm{x}) \in \mathrm{V}$ and $\mathrm{x} \in \mathrm{G}$. By the almost p-continuity of $f$, there exists an open set $\mathrm{U}$ in $\mathrm{X}$ containing $\mathrm{x}$ such that $f(\mathrm{U}) \subseteq \mathrm{pCl}(\mathrm{V})$. Therefore, we have $\mathrm{x} \in \mathrm{U} \cap \mathrm{G} \subseteq f^{-1}(\mathrm{pCl}(\mathrm{V})) \cap \mathrm{G}=f^{-1}(\mathrm{~V})$. Since $\mathrm{U} \cap \mathrm{G}$ is open in $\mathrm{X}, \mathrm{x}$ is an interior point of $f^{-1}(\mathrm{~V})$ and hence $f^{-1}(\mathrm{~V})$ is open in $\mathrm{X}$. This shows that $f$ is p-continuous.

A space $\mathrm{X}$ is said to be pre-regular [20] if for each preclosed set $\mathrm{A}$ and each point $\mathrm{x}$ in the complement of $\mathrm{A}$, there exist disjoint $\mathrm{V} \in \mathrm{PO}(\mathrm{X})$ and $\mathrm{W} \in \mathrm{PO}(\mathrm{X})$ such that $x \in V$ and $A \subseteq W . P a l$ and Bhattacharya [20, Lemma 4.2] has shown that a space $X$ is pre-regular if and only if for each point $\mathrm{x}$ of $\mathrm{X}$ and each $\mathrm{V} \in \mathrm{PO}(\mathrm{X}, \mathrm{x})$, there exists $\mathrm{W} \in \mathrm{PO}(\mathrm{X}, \mathrm{x})$ such that $\mathrm{x} \in \mathrm{V} \subseteq \mathrm{pCl}(\mathrm{V}) \subseteq \mathrm{W}$.

Theorem 4.2.A function $f: \mathrm{X} \rightarrow \mathrm{Y}$ is $\mathrm{p}$-continuous if and only if it is almost $\mathrm{p}$ continuous and $\mathrm{p}^{*}$-continuous.

Proof. Suppose that $f$ is p-continuous. It is evident that $f$ is almost p-continuous. For each $\mathrm{V} \in \mathrm{PO}(\mathrm{Y})$, we have $\mathrm{pFr}(\mathrm{V})=\mathrm{pCl}(\mathrm{V}) \cap \mathrm{pCl}(\mathrm{Y}) \mathrm{V})=\mathrm{pCl}(\mathrm{V}) \cap(\mathrm{Y} \backslash \mathrm{V})$. Since $f$ is $\mathrm{p}$ continuous, it follows that $f^{-1}(\mathrm{pFr}(\mathrm{V}))=f^{-1}(\tilde{\mathrm{pCl}}(\mathrm{V})) \cap f^{-1}(\mathrm{Y} \backslash \mathrm{V})$ is closed in $\mathrm{X}$. This shows that $\mathrm{p}$-continuity implies also $\mathrm{p}^{*}$-continuity. Conversely, for each $\mathrm{V} \in \mathrm{PO}(\mathrm{Y})$, we have

$\mathrm{pCl}(\mathrm{V})) \cap(\mathrm{Y} \backslash \mathrm{pFr}(\mathrm{V}))=\mathrm{pCl}(\mathrm{V}) \cap[\mathrm{Y} \backslash(\mathrm{pCl}(\mathrm{V}) \cap(\mathrm{Y} \backslash \mathrm{V}))]$

$=\mathrm{pCl}(\mathrm{V})) \cap[(\mathrm{Y} \backslash \mathrm{pCl}(\mathrm{V})) \cup(\mathrm{Y} \backslash(\mathrm{Y} \backslash \mathrm{V}))]$

$=\mathrm{pCl}(\mathrm{V})) \cap[(\mathrm{Y} \backslash \mathrm{pCl}(\mathrm{V})) \cup(\mathrm{V})]$

$=\mathrm{pCl}(\mathrm{V}) \cap \mathrm{V}=\mathrm{V}$

Thus we obtain $f^{-1}(\mathrm{~V})=f^{-1}(\mathrm{pCl}(\mathrm{V})) \cap f^{-1}(\mathrm{Y} \backslash \mathrm{pFr}(\mathrm{V}))$

$$
=f^{-1}(\mathrm{pCl}(\mathrm{V})) \cap\left[\mathrm{X} \backslash f^{-1}(\mathrm{pFr}(\mathrm{V}))\right] \text {. }
$$

Since $f$ is almost p-continuous and $\mathrm{pCl}(\mathrm{V})$ is pre-regular in $\mathrm{Y}, f^{-1}(\mathrm{pCl}(\mathrm{V}))$ is closed and open in $\mathrm{X}$. Since $f$ is $\mathrm{p}^{*}$-continuous, $f^{-1}(\mathrm{pCl}(\mathrm{V}))$ is closed in $\mathrm{X}$. It follows that $f^{-1}(\mathrm{~V})$ is open in $\mathrm{X}$ and hence $f$ is p-continuous.

\section{Conclusion}

In Section 3, we obtain some properties of p-continuous functions. Moreover, in Section 4, we show that a function $f: X \rightarrow Y$ is p-continuous if and only if it is almost p-continuous and relatively almost p-continuous. We also provide a decomposition of p-continuity. 
almost p-continuous and relatively almost p-continuous. We also provide a decomposition of p-continuity.

\section{Acknowledgements}

The author would like to thank Professor .M.E.Abd EL-Monsef for his valuable comments and suggestions.

\section{References}

[1] M.E. Abd El-Monsef, R.A. Mahmoud and A.A. Nasef, A class of functions stronger than Mprecontinuity, preirresoluteness and A-functions, Qatar Univ. Sci. Bull. 10(1990), 41-48.

[2] H.Blumberg, New Properties of all real functions, Trans.Amer. Math. Soc., 24 (1922), 113-128.

[3] H.H. Corson and E.Michael, Metrizability of certain countable unions, Illinois J. Math., 8 (1964), 351-360.

[4] A. Debray, Investigations of some properties of Topology and Certain Allied Structures, Ph.D. Thesis, Univ. of Calcutta, (1999).

[5] S.N. El-Deeb, I. A. Hasanein, A.S. Mashhour and T. Noiri, On p-regular space, Bull. Math. Soc. Sci. R.S. Roumanie 27 (75) (1993), 311-315.

[6]M.S. El Naschie, O.E. Rosster and G. Oed., Information and diffusion in quantum physics, Chaos, Solitons and Fractals, 7(5)(1996) [Special issue].

[7]M.S. El Naschie, The symplistic vacuum, exotic quasi-particles and gravitational instanton, Chaos, Solitons and Fractals, 22 (2004), 1-11

[8]M.S. El Naschie, Quantum gravity, Clifford algebra, fuzzy set theury and the fundamental constants of nature, Chaos, Solitons and Fractals, 20 (2004), 437-450.

[9] M. Ganster, Preopen sets and resolvable spaces, Kyungpook Math. J. 27(2) (1987), 135-143.

[10] M.Ganster, S. Jafari and T. Noiri, On pc-compact sapces, Mem. Fac. Sci. Kochi Univ. (Math.) 23 (2002), 19-26.

[11] S. Jafari, Pre-rarely p-continuous functions between topological spaces, Far East J. Math. Sci : (2000), 87-96.

[12] N. Levine, A decomposition of continuity in topological spaces, Amer. Math. Monthly 68 (1961), 44-46.

[13] N. Levine, Semi-open sets and semi-continuity in topological spaces, Amer. Math. Monthly, 70 (1963), 36-41.

[14] A.S. Mashhour, M.E. Abd El-Monsef and S.N. El-Deeb, On precontinuous and weak precontinuous mappings, Proc. Math. Phys. Soc. Egypt 53 (1982), 47-53.

[15]A.S. Mashhour, I.A. Hasanein and S.N. El-Deeb, $\alpha$-continuous and $\alpha$-open mappings, Acta Math. Acad. Sci. Hungar, 41 (1983), 213-218.

[16] S.A. Naimpally, Analysis the unknown, preprint.

[17]A.A. Nasef and A.A. Abo Khadra, Functions based on closeness, Proc. Math. Phys. Soc. Egypt, No 74 (1999), 7-16.

[18] T.M. Nour, Contributions to the Theory of Bitopological spaces, Ph. D. Thesis, Univ. of Delhi, 1989.

[19] V. Popa, T. Noiri and M. Ganster, On upper and lower almost precontinuous multifunctions, Far East J. Math. Sci. Special Vol. (1997), 49-68.

[20] M.C. Pul and P. Bhattacharys, Feebly and strong forms of preirresolute functions, Bull. Malaysian Math. Soc. (Second Series) 19 (1996), 63-75.

[21] A.D. Rose, Subweakly $\alpha$-continuous functions, Inter. J. of Math. and Math. Sci., 11 (4) (1988), 713-720. 


\section{بعض صفات الدوال المتصلة من النوع (p) وإحلالات جديدة}

\section{عرفة عبد الظاهر ناصف}

\section{حامعة كفر الشيخ ـ كلية الهندسة ـ قسمر الفيزيقا والرياضيات الهندسية}

$$
\text { فى هذا البحث تم تقديم نوعين من الدوال المتصلة هما: }
$$

Relatively almost p- continuity and p*- continuity

وتم الحصول على بعض نظريات الإحلال للاتصال من النوع (p) وذلك عن طريق إثبات النظريات الرئيسية التالية:

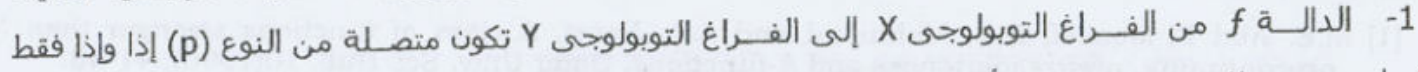

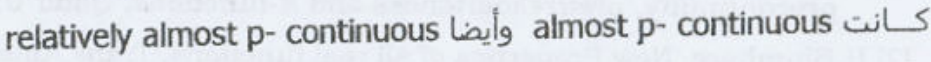

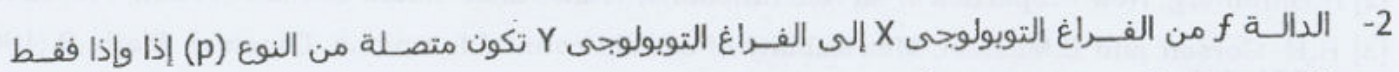
p*- contiuous وأيضت almost p- continuous 